\title{
Role of work overload and sleep deprivation in predicting work situation awareness among workers of a petrochemical industry
}

Fariba Kiani ${ }^{1}$, Seyed Hakime Safavi Mirmahale ${ }^{2}$, Mohammad Reza Khodabakhsh $^{3}$

\author{
Journal of Research \& Health \\ Social Development \& Health Promotion \\ Research Center \\ Vol. 6, No. 5, Nov \& Dec 2016 \\ Pages: 487- 494 \\ DOI: 10.18869/acadpub.jrh.6.5.487 \\ Original Article
}

1. Young Researchers and Elite Club, Shahrekord Branch, Islamic Azad University, Shahrekord, Iran

2. Department of Psychology, Rodehen Branch, Islamic Azad University, Rodehen, Iran

3. Correspondence to: Department of Psychology, Neyshabur Branch, Islamic Azad University, Neyshabur, Iran

Email: Khodabakhsh@ut.ac.ir

Received: 9 Feb 2015

Accepted: 5 Mey 2015

How to cite this article: Kiani F, Safavi

Mirmahale SH, Khodabakhsh MR. Role of work overload and sleep deprivation in predicting work situation awareness among workers of a petrochemical industry. $J$ Research \& Health2016; 6(5): 487- 494.

\begin{abstract}
Situation awareness is an important factor in the incidence of industrial accidents. Improving situation awareness may help to prevent occupational accidents. Determination of factors influencing the situation awareness will help to plan and implement the measures for improving working conditions and making a safer workplace. In this study, was examined the role of work overload and sleepiness in predicting work situation awareness among workers. It was a cross-sectional study. The sample consisting of 180 employees at a petrochemical industry was selected according to the random stratified sampling method. They were asked to respond to questionnaires including work situation awareness of Sneddon, Mearns \& Flin, work overload of Beehr, Walsh \& Taber, and Epworth sleepiness scale. The results showed that there was an internal correlation among work overload, sleepiness, and work situation awareness. Also, the results of stepwise regression analysis revealed that work overload and sleepiness significantly predicted, respectively, almost $10 \%$ and $24 \%$ of variances of work situation awareness among the workers. Thus, for improving workplace safety, interventional measures can focus on enhancing situation awareness via workload and sleepiness reduction.
\end{abstract}

Keywords: Awareness, Sleep Deprivation, Workers, Workload

\section{Introduction}

After a number of catastrophic events, companies and industries are making every effort to ensure that their occupational accident rates are kept as low as possible [1]. In most occupational accidents, there is a causal chain of organizational conditions and person errors. Reason [2] conclude that human-factor causes can be attributed to $70-80 \%$ of occupational accidents in high-hazard industries. One critical element in predicting occupational accidents is the ability of employees to maintain an adequate understanding of their work situation. This means having a high level of awareness about job duties and workplace conditions, and judging how these may change in the near future to predict how the situation will develop [3]. Cognitive psychologists have long been interested in attention [4], 
and hence, the role of cognitive skills in safety issues is well documented [5]. In industrial companies, the necessary attentional skills are referred to as 'situation awareness' (SA). SA is defined as "the perception of the elements in the environment within a volume of space and time, the comprehension of their meaning, and the projection of their status in the near future" [6]. According to this definition, SA is the first step in decision-making because it provides an understanding of what is happening and what is likely to occur next, and has been described as an inherent model for safe decision-making. The SA has been further studied in aviation industry [7]; in recent years, the study has performed in other fields such as aircraft maintenance, driving, etc [8]. Cognitive skills such as work situation awareness are known to be susceptible to the elements of work-related conditions such as work overload and sleep deprivation [9] which are common in many high-risk industries and organizations, for example in oil and gas exploration [10]. Ongoing research of the causal events shows failures in situation awareness and risk assessment [11]. So, it is important to identify factors reducing work situation awareness.

Unusually high workloads can affect individuals' performance [12]. Work overload was defined as "a hypothetical construct that represents the cost incurred by a human operator to achieve a particular level of performance" [13]. If workload is high or the tasks are very complicated, it can mean that workers are involved by attending particular tasks, or are distracted by other pressing issues to tackle and so, they do not apportion adequate time to monitor their work situation. In doing so, their situation awareness will be damaged, as they may be unaware of situational changes, and may make improper decisions based on incomplete or incorrect data [14]. Consequently, they may also be unable to react adequately fast when an unforeseen incident occurs. Although oil and gas industries try to maintain the correct balance between production pressures and safety [15], in today's energy market, changing demand is an intrinsic characteristic of the oil working environment and therefore the rate of work being done does not always occur at a constant level. Low workload phases do occur (e.g. waiting on weather), but more typical are periods when workload sharply increases (e.g. due to production pressures, or when the number of workers in workplace is low). Studies indicate that increased workload has a detrimental effect on workers' psychological wellbeing [16].

Also, sleepiness causes damages to alertness levels and consequently increases the risk involved in the job injuries [17], as the cognitive resources required are depleted due to physical actions or sleep deprivation [18]. Dawson and Reid [19] concluded that defects in cognitive processing in persons with only moderate sleep deprivation and fatigue were similar to those experienced when blood alcohol levels are over the legal limit for driving. The effects of fatigue due to sleepiness are appeared as reduction in the speed of cognitive processing, and therefore increased reaction time, tunnel vision, inattentiveness, and lower vigilance and concentration [20]. In attention to above materials, the aim of the current research was to investigate the relationship between work overload and sleepiness and work situation awareness. So far, a few researches (particularly in Iran) have been carried out on the work situation awareness and the present research is new on this subject.

\section{Method}

This cross sectional study was administrated between October and November 2014 at a petrochemical industry in Asalooyeh area, Iran. In this study, considering the extent and distribution of the employees in the different parts of the company, random stratified sampling method was used to select the participants. These subsets of the strata are then pooled to form a random sample. Then, simple random sampling or systematic sampling was applied within each stratum. This approach often improves the representativeness of the sample by reducing sampling error. It can 
produce a weighted mean with less variability than the arithmetic mean obtained from a simple random sampling method. The sample size was calculated using SPSS-19, following the procedure recommended by Molavi [21]. Given an alpha level of 0.05 and a power of 90 percent, the sample size required was estimated to be 180 participants. Given the likelihood of failure to complete or return the questionnaires, almost 190 employees were selected using random stratified sampling and questionnaires were distributed to them. Informed consent was obtained from each participant and the research was approved by the appropriately constituted ethics committees where the work was conducted. The inclusion criterion was the employees with at least one year work experience. The individuals with incomplete questionnaires and lack of interest in participating in the research, and employees with current and/or history of mental disorders or accidents affecting the musculoskeletal system were excluded from the study. Four members of the participants due to lack of interest in the research topic, and six members due to the incomplete questionnaires (in total 10 members) were excluded of the main sample. Thus, 180 completed questionnaires were collected. Participants were assured that their information will remain confidential and they were free to exit the study whenever they wanted to.

Validated instruments were used for data collection on work situation awareness, work overload and sleepiness. At first, all the questionnaires were translated from English into Persian and independently back-translated into English by a second translator. The few discrepancies between the original English and the back-translated version resulted in adjustment in the Persian translation based on direct discussion between the translators. At next step, psychometric characteristics of instruments were examined. Linguistic validation was performed by three experts of psychology department and five experts of safety and health departments. Then, the questionnaires were piloted and finalized with an advisory group of workers to ensure that the scaling the items was comprehensible and appropriate to the context. Moreover, conceptual analysis confirmed the content validity of all the instruments. The questionnaires were distributed to the workers with the help of union steward. The following questionnaires were used:

Work situation awareness (SA): SA was measured by using the 20-item questioner of Sneddon, Mearns, Flin [22]. Respondents indicated the extent of agreement with each statement on a 5 -point Likert-type scale $(0=$ very often; $5=$ never). The questions of this scale consisted of 5 positive questions such as: "I think ahead of my work to plan for different possible outcomes" and 15 negative questions such as: "I am easily distracted by my thoughts or feelings". Sneddon and et al. [22], in their study, have shown an acceptable internal reliability (Cronbach's alpha $=0.86$ ) and a good validity for this scale. Evidence of reliability of this scale, as administered to Iranian relevant population, in this research is 0.79 by Alpha Coefficient and 0.75 by Splithalf. The validity coefficients of questions are between 0.25 and 0.79 , all are significant at $\mathrm{p}<0.0001$. Work Overload: This scale was measured by using 4-item questioner of Beehr, Walsh and Taber [23]. The scale refers to general perceptions about whether there is work density (eg, hours of work) in the job or not. Two example questions of this scale were "I am so busy on the job that can't get to take normal breaks" and "There is too much work to do in my job for it all to be done well". Participants showed their extent of agreement with each statement on a 5-point Likerttype scale $(1=$ strongly disagreed; $5=$ strongly agreed). Mantineau [24] reported the internal validity of this scale using Cronbach's alpha as 0.83 . Also, she showed that this scale had good criterion validity. Internal consistencies (Cronbach's $\alpha$ ) in this study in Iran were 0.79, which was good for this scale.

Epworth Sleepiness Scale (ESS): The sleep assessment was based on a sleep scale, the ESS with eight items [25]. This 8item 
questionnaire has been designed to determine a participant's likelihood to doze off or fall asleep in different situations. An example item is "How likely are you to doze off or fall asleep in the following situations, in contrast to feeling just tired? For example, sitting and talking to someone". All items are rated on a scale of $0-3$; a score above 10 is considered positive for excessive daytime sleepiness (EDS) [26]. This scale is one of the most widely subjective methods used to measure EDS. It is a questionnaire-based scale; its application is brief and simple, with minimal cost involved. In addition, this scale has a suitable level of internal consistency for application in studies. The cutoff score higher than 10 has $93.5 \%$ sensitivity and $100 \%$ specificity to distinguish
EDS from normal daytime sleepiness [25]. Evidence of reliability of this inventory, as administered to Iranian relevant population, in this research, was calculated by Alpha Coefficient equal to 0.77 and by Split-half equal to 0.73 . The validity coefficients of questions are between 0.23 and 0.88 , which all are significant at $\mathrm{p}<0.0001$. The Statistical Package for the Social Sciences SPSS-19 was used to analyze the data. Also, descriptive statistics was used to summarize and organize the data. The data were also analyzed by stepwise regression analysis.

\section{Results}

Demographic characteristics of the participants in this study are presented in Table 1 .

Table 1 Demographic characteristics of the sample members $(N=180)$

\begin{tabular}{cccc}
\hline & & Frequency & Frequency Percentage (\%) \\
\hline \multirow{3}{*}{ Age } & 18 to 29 years & 49 & $27.5 \%$ \\
& 30 to 41 years & 122 & $67.5 \%$ \\
& 42 to 53 years & 9 & $5 \%$ \\
\hline \multirow{2}{*}{ Sex } & Male & 180 & $100 \%$ \\
& Female & - & - \\
\hline \multirow{2}{*}{ Marital } & Married & 162 & $90 \%$ \\
status & Single & 18 & $10 \%$ \\
\hline \multirow{4}{*}{ Education } & M.Sc. (M.A.) degree or higher & 58 & $32.5 \%$ \\
& B.Sc. (B.A.) degree & 49 & $27.5 \%$ \\
& High school graduates & 73 & $40 \%$ \\
\hline \multirow{3}{*}{ Work } & Primary school graduates and lower & - & - \\
experience & 5 years and lower & 63 & $35 \%$ \\
& 6 to 15 years & 43 & $24 \%$ \\
\hline \multirow{2}{*}{ Shift status } & 16 to 25 years & 43 & $24 \%$ \\
& 26 years and higher & 31 & $17 \%$ \\
\hline
\end{tabular}

Mean, standard deviation and internal correlations of variables under the study are presented in Table 2.
As can be seen, there were significant relationships between work overload, sleepiness, and work situation awareness $(\mathrm{p}<0.01)$.

Table 2 Mean, error standard and pearson correlation coefficients

\begin{tabular}{lccccc}
\hline & \multicolumn{5}{c}{ Correlations } \\
\cline { 2 - 6 } & $\overline{\boldsymbol{X}}$ & SD & 1 & 2 & 3 \\
\hline 1. Work overload & 22.89 & 4.13 & 1 & & \\
2.Sleepiness & 66.97 & 7.21 & $0.24^{* *}$ & 1 & \\
3.Work situation awareness & 64.55 & 6.22 & $-0.34^{* *}$ & $-0.51^{* *}$ & 1 \\
\hline$* * \mathrm{p}<0.001$ & & & & &
\end{tabular}

To assess the predictive power of work situation awareness by work overload and sleepiness variables, the stepwise regression analysis was used. Initially, the assumptions of regression analysis were tested as follows. 1) The normality of the error distribution was tested by Anderson-Darling statistic. The acceptable Durbin-Watson range is between 1.5 and 2.5. 
In this analysis, Durbin - Watson value of 2.115 was obtained, which is within the acceptable range. This value shows that there was not auto correlation problems in the data used in this research. 2) Two major methods were utilized in order to determine the presence of multicollinearity among independent variables in this study. These methodologies involved in the calculation of both a Tolerance test and Variance Inflation Factor (VIF). The results showed in this data, i) none of the tolerance levels is <or equal to .01; and ii) all VIF values are well below 10 . Thus, the measures selected for assessing independent variables in this study do not reach the levels indicating multicollinearity. 3) Observing the error distribution curve shows that this curve is normal because its' mean value is small and close to zero and its' standard deviation is close to one and equal to 0.952 . Also, the normality test was conducted by using KolmogorovSmirnov nonparametric test. The test statistic $(\mathrm{z}=0.77)$ showed that the significance level is more than $5 \%$. Thus, the null hypothesis of normal distribution for variables is comparable at $95 \%$ accepted level.

The results of model summary are presented in Table 3.

Table 3 Summary of stepwise regression analysis model

\begin{tabular}{lccccc}
\hline Variable & $\mathrm{R}$ & $\mathrm{R}^{2}$ & $\Delta \mathrm{R}^{2}$ & $\Delta \mathrm{F}^{2}$ & Sig. \\
\hline Step 1: Sleepiness & 0.51 & 0.26 & 0.26 & 62.72 & .000 \\
Step 2: Sleepiness and work overload & 0.58 & 0.33 & 0.07 & 19.33 & .000 \\
\hline
\end{tabular}

The results of regression model for explaining work situation awareness based on work overload and sleepiness indicated that F-statistic for both models is significant at $\mathrm{p}<0.001$. Therefore, there was possibility of explanation of work situation awareness based on both variables. In Table 4, the regression coefficients of stepwise regression analysis are presented.

Table 4 Summary of stepwise regression analysis to predict work situation awareness based on work overload and sleepiness

\begin{tabular}{lcccccc}
\hline Variable & $\beta$ & $\mathrm{B}$ & $\mathrm{SE} \mathrm{B}$ & $\mathrm{t}$ & $\mathrm{R}^{2}$ & Sig. \\
\hline Sleepiness & -0.47 & -1.16 & 0.15 & -7.55 & 0.24 & .000 \\
Work overload & -0.27 & -1.07 & 0.24 & -4.40 & 0.10 & .000 \\
\hline
\end{tabular}

As can be seen, sleepiness variable with $\beta=-$ 0.47 can significantly predict almost $\% 24$ of the variance of work situation awareness. Also, work overload variable with $\beta=-0.27$ can significantly predict almost $\% 10$ of the variance of work situation awareness.

\section{Discussion}

The results showed that work overload significantly predicted work situation awareness among workers. This is consistent with the findings of the previous studies [27,28] and can be interpreted on the basis of the following possibilities:

Several researches indicated how the concepts of workload, situation awareness, and safety performance are related to each other for individual operators [29]. These models generally indicate that work overload has a negative impact on work situation awareness which in turn has a positive correlation with incidents among workers. That is, as workload increases, situation awareness decreases and subsequently safety performance worsens.

A Structural Equation Model (SEM) [30] indicates that the theoretical constructs of SA, workload, and safety performance are related and affect each other, so that the workload negatively affects the SA, a low SA enables disturb safety performance. Also, work overload can result in increasing stress levels among workers that can cause the reduced working memory capacity and diminished attention [31]. Work overload can also result in poor concentration/alertness due to an overload on the personnel's cognitive resources, and this can interfere with the primary perception of the situation and conditions, causing inattention to 
the available information [31].

Sawaragi and Murasawa [32] concluded that the high workload of the task demands can affect much the decision maker's internal reasoning tasks, and the internal states of the cognitive processing within a decision maker. The interaction complexity can affect worker's ability to aware of work situation. In another study, Hancock and Warm [33] showed that performance is especially disturbed when a worker is cognitively overloaded. Workers seek to meet task demands but as demands become excessive, they become overloaded and performance decrements occur. Requiring workers to maintain awareness of their work situation and make efficient decisions while serving long and intense shifts could result in cognitive overload.

Also, the results showed sleepiness variable significantly predicted work situation awareness among the workers. This is consistent with the findings of the previous studies [34] and can be interpreted on the basis of the following possibilities:

Wallace et al.'s [34], in their research, concluded that individuals who scored higher on day-time sleepiness and fatigue also experienced more cognitive failures. Fatigue due to sleep disruption in petroleum and chemical industries is part of working conditions and these results show that this is detrimental to employees through decreasing their work situation awareness levels. Lorist and et al. [35] concluded that mental and physical fatigue cause to impaired cognitive control and decreased situation awareness. Mc Donald and et al. [36] by conducting the simple tests of attention and concentration indicated that some impairment in situation awareness was influenced by fatigue and sleepiness. They concluded that decreased attention and increased cognitive errors are an obvious result of fatigue among employees. So, tired workers lose their vigilance and alertness, and therefore cannot pay attention to the workplace conditions. Wallace et al. [37] found that the daytime sleepiness related significantly to their 'distractions' factor. Sleep deprivation results in degraded perception and vigilance, as well as increased distractibility and confusion. Each of these factors affects an individual's ability to safely work and may play a central role in accidents and injuries. Connor et al. [38] found that there were relationships between sleepiness and risk of injury resulting from an accident. Individuals with less than five hours of sleep in the 24 hours prior to the crash had a significantly higher risk of a crash resulting from the accident compared to individuals who had more than five hours of sleep.

\section{Conclusion}

The findings of this research emphasize the importance of work overload and sleepiness variables in predicting work situation awareness among the workers. Safety intervention needs to focus on these variables, as well as on the prevention methods coping against them, and these concepts influence the increase of work situation awareness directly or indirectly. It is recommended that the future researches examine the effects of safety interventions on increasing situation awareness. Furthermore, with designing these interventions and with more attention to them, we can affect one of the most important influential variables on the incidence of occupational accidents. The present study needs to be replicated in different populations and needs more empirical support. Till then, the findings of the study should be interpreted with caution. Further, the cross-sectional design of the study and participants (i.e., a group of employees) exert some limitations on the generalization of the findings. Finally, the problems and limitations in the use of self-repotting instruments should not be overlooked.

\section{Acknowledgements}

The authors would like to acknowledge the generosity of workers who agreed to participate in this research.

\section{Contribution}

Study design: FK

Data collection and analysis: FK, MRK

Manuscript preparation: FK, MRK. 


\section{Conflict of Interest}

"The authors declare that they have no competing interests."

\section{Funding}

The author (s) received no financial support for the research, authorship and/or publication of this article.

\section{References}

1- Adie W, Cairns JA, Macdiarmid J, et al. Safety culture and accident risk control: Perceptions of professional divers and offshore workers. Safety Science2005; 43(2): $131-45$.

2- Reason J. Human error: models and management. BMJ2000; 320(7237): 768-70.

3- Stanton N, Chambers P, Piggott J. Situational awareness and safety. Safety Science2001; 39(3): 189-204.

4- Styles EA. The psychology of attention. High Wycombe: Buckinghamshire College, Bucks, UK psychology press; 2006.

5- Strater O. Cognition and safety: an integrated approach to system design and assessment. Aldershot, England: Ashgate; 2005.

6- Wright SM, Fallacaro MD. Predictors of situation awareness in student registered nurse anesthetists. AANA J2011; 79 (6), 484-90.

7- Sitterding MC, Broome ME, Everett LQ, Ebright P. Understanding situation awareness in nursing work: a hybrid concept analysis. ANS Adv Nurs Sci2012; 35(1): 77-92.

8- Adams MJ, Tenney YJ, Pew RW. Situation awareness and the cognitive management of complex systems. Human Factors 1995; 37(1): 85-104.

9- Sexton JB, Thomes EJ, Helmreich RL. Error, stress and teamwork in medicine and aviation: cross-sectional surveys. BMJ2000; 18; 320(7237): 745-9.

10- Flin R, Slaven G. Managing the offshore installation workforce. Oklahoma: Penwell books; 1996.

11- Skogdalen JE, Vinnem JE. Quantitative risk analysis of oil and gas drilling, using deepwater Horizon as case study. Reliab Eng Syst Safe2012; 100(2): 58-66.

12- Hockey GR. Compensatory control in the regulation of human performance under stress and high workload: a cognitive-energetical framework. Biol Psychol1997; 45(1-3): 73-93.

13-Hart SG, Staveland LE. Development of a multidimensional workload rating scale: results of empirical and theoretical research. Human mental workload. Amsterdam: Elsevier; 1988. PP: 139-83.

14- Jeannot E. Situation awareness, synthesis of literature search. Eurocontrol experimental centre; 2000. [4 screens]. Available atURL: https://www.eurocontrol.int/eec/ gallery/content/public/document/eec/report/2000/031 Situation_Awareness_Literature_Search.pdf. Accessed Jun27 2000

15- Mearns K, Whitaker SM, Flin R. Safety climate, safety management practice and safety performance in offshore environments. Safety Science2003; 41(8):64180.

16- Parkes K. Mental health in the offshore oil industry: a comparative study of onshore and offshore employees. Psychol Med1992; 22(4): 997-1009.

17- Folkard S, Lombardi DA. Toward a "risk index" to assess work schedules. Chronobiol Int2004; 21(6): 1063-135.

18- Rosekind M, Gander P, Miller D, et al. Fatigue in operational settings: examples from the aviation environment. Hum Factors 1994; 36(2): 327-38.

19-Dawson D, Reid K. Fatigue, alcohol and performance impairment. Nature 1997; 388(6639): 235.

20- Helmreich RL, Musson DM, Sexton JB. Human factors and safety in surgery. Surgical patient safety: essential information for surgeons in today's environment. Chicago: American college of surgeons; 2004.

21- Molavi H. SPSS 10-13-14 applied guidance in behavioral sciences. 2ed. Isfahan: Poyesh andishe publication; 2007.

22- Sneddon A, Mearns K, Flin R. Stress, fatigue, situation awareness and safety in offshore drilling crews. Safety Science 2013; 56(2): 80-8.

23- Beehr TA, Walsh JT, Taber TD. Relationship of stress to individually and organizationally valued states: higher order needs as a moderator. $J$ Occup Psychol1976; 61(7): 41-7.

24- Munteanu MR. Safety attitudes in the ontario construction. Master's thesis in applied science and engineering. Canada: University of Toronto; 2005.

25- Canani SF, John AB, Raymundi MG, Schonwald S, Menna Barreto SS. Prevalence of sleepiness in a group of Brazilian Lorry drivers. Public Health2005; 119(10): 925-9.

26- Melamed S, Oksenberg A. Excessive daytime sleepiness and risk of occupational injuries in non-shift daytime workers. Journal of Sleep and Sleep Disorders Research2002; 25(3): 315-22.

27- Erland A, Svensson E, Wilson GF. Psychological and psycho-physiological models of pilot performance for systems development and mission evaluation. Int $J$ Aviat Psychol2002; 12(1): 95-110.

28- Svensson E, Angelborg-Thanderz M, Sjöberg L. Mission challenge, mental workload and performance in military aviation. Aviat Space Envir Med1993; 64(11): 985-1076.

29- Nählinder S, Berggren P, Svensson E. Reoccuring lisrel patterns describing mental workload, situation 
awareness and performance. Proceedings of the human factors and ergonomics society 48th annual meeting. LA: New Orleans; 2004.

30- Jöreskog K, Sörbom D. Lisrel 8: structural equation modeling with the Simplis command language. Hove: scientific software international (SSI); 1998.

31- Hancock PA, Szalma JL. Performance under stress. England: Ashgate publishing, aldershot; 2008.

32- Sawaragi T, Murasawa K. Simulating behaviors of human situation awareness under high workloads. Artif Intell Eng2001; 15(4): 365-81.

33- Hancock PA, Warm, JS. A dynamic model of stress and sustained attention. Hum Factors 1989; 31(5): 519-37. 34- Wallace JC, Vodanovich SJ, Restino BM. Predicting cognitive failures from boredom proneness and daytime sleepiness scores: an investigation within military and undergraduate samples. Pers Indiv Differ2003; 34(4): 635-44.

35- Lorist MM, Boksem MA, Ridderinkhof KR. Impaired cognitive control and reduced cingulate activity during mental fatigue. Brain Res Cogn Brain Res2005; 24(2): 199-205.

36- Mc Donald E, Cope H, David A. Cognitive impairment in patients with chronic fatigue: a preliminary study. $J$ Neurol Neurosur Psychiatry1993; 56(7): 812-5.

37- Wallace JC, Vodanovich SJ, Restino BM. Predicting cognitive failures from boredom proneness and daytime sleepiness scores: an investigation within military and undergraduate samples. Pers Indiv Differ2003; 34(4): 635-44.

38- Connor J, Norton R, Ameratunga S, et al. Driver sleepiness and risk of serious injury to car occupants: population based case control study. BMJ2002; 324(7346): 1125 . 